\title{
Simulation of Edge Plasmas in DIII-D Double- Null Configurations
}

\author{
M.E. Rensink, C.J. Lasnier, T.W. Petrie, G.D. Porter, \\ T.D. Rognlien
}

This article was submitted to The $8^{\text {th }}$ International Workshop on Plasma Edge Theory in Fusion Devices, Espoo, Finland, September 10-12, 2001

\section{September 6, 2001}

U.S. Department of Energy

Lawrence

Livermore

National

Laboratory

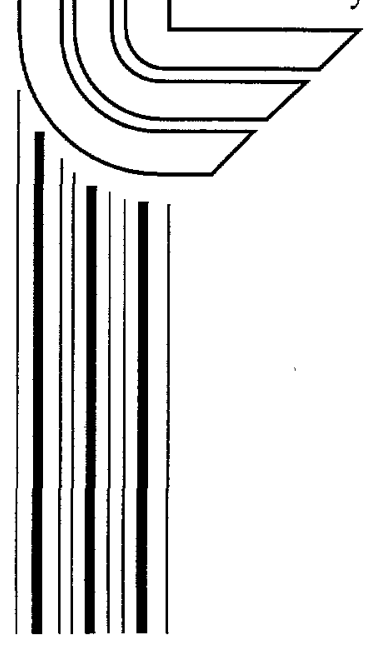




\section{DISCLAIMER}

This document was prepared as an account of work sponsored by an agency of the United States Government. Neither the United States Government nor the University of California nor any of their employees, makes any warranty, express or implied, or assumes any legal liability or responsibility for the accuracy, completeness, or usefulness of any information, apparatus, product, or process disclosed, or represents that its use would not infringe privately owned rights. Reference herein to any specific commercial product, process, or service by trade name, trademark, manufacturer, or otherwise, does not necessarily constitute or imply its endorsement, recommendation, or favoring by the United States Government or the University of California. The views and opinions of authors expressed herein do not necessarily state or reflect those of the United States Government or the University of California, and shall not be used for advertising or product endorsement purposes.

This is a preprint of a paper intended for publication in a journal or proceedings. Since changes may be made before publication, this preprint is made available with the understanding that it will not be cited or reproduced without the permission of the author.

This work was performed under the auspices of the United States Department of Energy by the University of California, Lawrence Livermore National Laboratory under contract No. W-7405-Eng-48.

This report has been reproduced directly from the best available copy.

Available electronically at http://www.doc.gov/bridge

Available for a processing fee to U.S. Department of Energy

And its contractors in paper from

U.S. Department of Energy

Office of Scientific and Technical Information

P.O. Box 62

Oak Ridge, TN 37831-0062

Telephone: (865) 576-8401

Facsimile: (865) 576-5728

E-mail: reports@adonis.osti.gov

Available for the sale to the public from

U.S. Department of Commerce

National Technical Information Service

5285 Port Royal Road

Springfield, VA 22161

Telephone: (800) 553-6847

Facsimile: (703) 605-6900

E-mail: orders@ntis.fedworld.gov

Online ordering: http://www.ntis.gov/ordering.htm

OR

Lawrence Livermore National Laboratory

Technical Information Department's Digital Library

http://www.llnl.gov/tid/Library.html 
Contrib. Plasma Phys. vol (year) num, p-p

\title{
Simulation of Edge Plasmas in DIII-D Double-Null Configurations
}

\author{
M.E. Rensink ${ }^{a}$, C.J. Lasnier ${ }^{a}$, T.W. Petrie ${ }^{b}$, G.D. Porter ${ }^{a}$, \\ T.D. ROGNLIEN ${ }^{\mathrm{a}}$ \\ ${ }^{a}$ Lawrence Livermore National Laboratory, Livermore, CA 94550, USA \\ ${ }^{\mathrm{b}}$ General Atomics, San Diego, CA 92138, USA \\ e-mail:rensink1@llnl.gov
}

\begin{abstract}
We present fluid model simulation results for the edge plasma in the DIII-D tokamak with unbalanced double-null magnetic configurations, including cross field drifts. Input parameters are typical of low-power operation in DIII-D. For high-recycling the plasma tends to be detached from all divertor plates. Midplane plasma and electric field profiles are relatively insensitive to the magnetic imbalance. Divertor heat flux profiles exhibit sharp peaks due to cross-field drifts when the ion grad-B drift direction is away from the $\mathrm{x}$-point toward the magnetic axis.
\end{abstract}

\section{Introduction}

Most tokamaks are operated in a poloidal divertor configuration to facilitate the removal of particles and heat from the core plasma. A single-null divertor configuration is commonly used, but there are some potential advantages for double-null configurations which distribute the plasma exhaust over four divertor plates rather than two. For a conventional lower single-null configuration the maximum heat flux is on the outboard divertor plate while the maximum plasma density is at the inboard divertor plate. Cross-field drifts have been shown to play a significant role in defining this inboard/outboard divertor plasma asymmetry for a single-null configuration [1]. The asymmetry can be substantially altered by reversing the sign of the toroidal magnetic field or by operating the tokamak in an upper single-null configuration. In a double-null configuration we expect a similarly important role for the cross-field drifts in determining the inboard/outboard and up/down plasma asymmetries. In a doublenull configuration, the two x-points may not lie on the same magnetic flux surface, so there will be a primary and secondary divertor, depending on the magnetic imbalance. One can quantify this imbalance in terms of dRsep [2], the radial distance between the upper divertor separatrix and the lower divertor separatrix, as measured at the outboard midplane. In the DIII-D tokamak it is possible to vary the magnetic configuration in a continuous manner from lower single-null (dRsep $<0$ ) to balanced double-null to upper single-null $(\mathrm{dRsep}>0)$. In this paper we report results of edge plasma simulations in double-null configurations with varying degrees of magnetic imbalance and we include the effect of cross-field drifts. A comparison with experimental results is deferred to a future publication when more extensive simulation results are available. 


\section{$2 \quad$ Model}

We simulate the edge plasma of a tokamak using the UEDGE code [3]. This is a twodimensional multi-fluid model that includes classical plasma transport along field lines and cross-field drifts together with anomalous radial transport. The self-consistent electrostatic potential is calculated via quasi-neutrality and current continuity[4]. Although the model can accomodate any number of impurity species, we include only hydrogenic ions and neutrals in these simulations. The neutrals are described here via a simple diffusive model. Toroidal symmetry is assumed and the simulation domain, illustrated in Figure 1, is based on poloidal flux surfaces in the core and edge regions of the plasma, including all divertor plates. The magnetic flux surfaces are derived from MHD equilibria that fit the magnetic data for various DIII-D shots and time slices. For the simulations for this report we use orthogonal meshes in which the divertor plates are oriented perpendicular to the flux surfaces in the various divertors. The separatrix strike points are located at the correct positions corresponding to the actual divertor plates in DIII-D. The "standard" direction of the toroidal magnetic field is out of the paper in Figure 1, so the ion-grad-B drift is downward toward the lower $\mathrm{x}$-point for these simulations.

The main inputs for the UEDGE plasma are the total power to the edge plasma at the core boundary, $\mathrm{P}_{\text {core }}=2.5 \mathrm{MW}$, the plasma density on the core boundary, $\mathrm{n}_{\text {core }}=$ $3 \times 10^{19} \mathrm{~m}^{-3}$ (at the $97 \%$ flux surface), the anomalous radial transport coefficients, $\mathrm{D}_{\perp}$ $=\chi_{\perp}^{e}=\chi_{\perp}^{i}=0.5 \mathrm{~m}^{2} \mathrm{sec}^{-1}$, and the recycling coefficients at the divertor plates and walls, $R_{p}=0.98$ and $R_{w}=0.9$. We assume all divertor plates are electrically grounded. Standard sheath conditions apply at the interface between the plasma and plates. These input parameters are typical of low-power DIII-D operation.

\section{Results}

Simulations of full double-null plasmas were first presented in References [5] and [6] for magnetically balanced configurations. The following results extend that capability to simulations with varying degrees of magnetic imbalance, including cross-field drifts. The mesh configurations are based on DIII-D MHD equilibria fit to a series of shots in which the dRsep was swept continuously from $-2 \mathrm{~cm}$ (lower single null) to $+2 \mathrm{~cm}$ (upper single null). Since the radial scale length of the heat flux profile in the SOL is typically of order $1 \mathrm{~cm}$ or less, we chose to simulate three configurations dRsep = $-1,0,+1 \mathrm{~cm}$ as representative of the experimental scan in dRsep. These simulations encompass the full double-null geometry, simultaneously including both upper and lower divertors.

\subsection{Divertor Plate Recycling}

The divertor plasma parameters are sensitive to the particle recycling coefficient, $R_{p}$, at the target plates. We expect nearly $100 \%$ recycling due to rapid saturation of the carbon divertor plates in DIII-D. However, at low input power $\left(\mathrm{P}_{\text {core }} \approx\right.$ a few $\left.\mathrm{MW}\right)$ the plasma tends to thermally detach from all divertor plates as $\mathrm{R}_{p}$ approaches $100 \%$ and it becomes difficult to find converged steady state solutions with the UEDGE code. Results of a parameter scan on $R_{p}$ for the magnetically balanced configuration are given in Figure 2. This figure shows the electron temperature profiles at the lower outboard divertor plate for various plate recycling coefficients and indicates that the 
plasma is nearly detached $\left(T_{e}<2 \mathrm{eV}\right)$ for $R_{p}=0.98$. We use this value for the dRsep scan results that follow.

\subsection{Midplane Profiles}

The plasma density and electron temperature profiles at the outboard midplane are very similar for all three dRsep configurations as shown in Figure 4 . The gradient scale length for the temperature is about $0.6 \mathrm{~cm}$ at the last closed flux surface, considerably smaller than the $\mathrm{dRsep}= \pm 1 \mathrm{~cm}$ for the unbalanced configurations, so we expect most of the heat to be conducted to the dominant divertor. The density profile is considerably broader than $1 \mathrm{~cm}$ so the plasma particle flux on the divertor plates may be less sensitive to dRsep for these cases. The midplane plasma profiles do not appear to be sensitive to the magnetic configuration parameter, dRsep.

\subsection{Divertor Profiles}

The heat flux profiles at each of the four divertor plates is plotted in Figure 4 . We superimpose results for the three magnetic configurations with $\mathrm{dRsep}=-1,0,+1$ $\mathrm{cm}$. The spatial coordinate is mapped back to the midplane and expressed as a radial displacement from the last closed flux surface. For the magnetically balanced case $(\mathrm{dRsep}=0)$ the peak heat flux in the lower divertor is about four times larger at the outboard plate compared to the inboard plate. The narrow spike in the heat flux profile at the upper outboard divertor plate for $\mathrm{dRsep}=+1 \mathrm{~cm}$ is also seen in the electron temperature (up to $20 \mathrm{eV}$ ) and the electrical current density profiles (not shown here). The high electron temperature means high thermal and electrical conductivity, so it is not surprising that the electron temperature profile correlates with high heat flux and electrical current. There is a hint of this same spike in the heat flux profile for the magnetically balanced case also. For the unbalanced cases one can see a weak heat flux in the secondary divertor beyond the $1 \mathrm{~cm}$ position (where the seconday separatrix strikes the divertor plate). The temperature of the plasma in the secondary divertor is less than $2 \mathrm{eV}$, but the ion density is substantial $\left(n_{i} \approx 10^{20} \mathrm{~m}^{-3}\right)$.

\subsection{Global Power and Particle Balance}

The total power deposited on each of the divertor plates is given in Table 1 for the three magnetic configurations with varying degrees of magnetic imbalance. The total heat flux across the outboard/inboard portions of the core flux surface is 2.15/0.35 for $\mathrm{dRsep}=0$ and this splits in the up/down direction differently on inboard and outboard halves. The surface areas of the outboard/inboard portions of the core are $36 / 15 \mathrm{~m}^{2}$. Since the heat flux ratio is about 6 and the surface area ratio is only 2.5 , there must be a significant contribution due to the steeper gradients at the outboard separatrix. In the absence of cross-field drifts for $\mathrm{dRsep}=0$ we would expect the power to split equally between upper and lower divertors, but the lower divertor actually gets 1.06 MW versus $0.81 \mathrm{MW}$ for the upper divertor due to the drifts.

There is a net source of particles at the core boundary which flows across the last closed flux surface and is pumped out of the system at the sidewalls and divertor

plates. For the magnetically balanced case this net ion source from the core is 1200 Amps and flows mainly to the outboard SOL; most of this is pumped at the outboard divertor plates (300 A at lower plate and $430 \mathrm{~A}$ at upper plate). 


\begin{tabular}{|l|l|l|l|}
\hline dRsep & $-1 \mathrm{~cm}$ & $0 \mathrm{~cm}$ & $+1 \mathrm{~cm}$ \\
\hline Lower-inboard & 0.40 & 0.22 & 0.07 \\
Lower-outboard & 1.21 & 0.84 & 0.20 \\
Upper-inboard & 0.05 & 0.24 & 0.67 \\
Upper-outboard & 0.15 & 0.57 & 0.86 \\
\hline
\end{tabular}

Tab. 1: Total Power (MW) to Divertor Plates

\section{Discussion}

The computational mesh for these simulations consists of 110 poloidal zones and 28 radial zones. These zones are distributed non-uniformly over the simulation domain so as to resolve steep gradients near the divertor plates and $\mathrm{x}$-points. However, steep gradients observed in the electrostatic potential and electrical current density near the $\mathrm{x}$-points are only marginally resolved by our mesh, so some details of the solutions may change with the mesh size.

Radial electric field profiles at the outboard midplane are similar for all dRsep. The field is negative in the core region and positive just outside the last closed flux surface, so the sheared radial electric field gives rise to sheared ExB poloidal flow which may suppress turbulence in the edge plasmá.

\section{Summary}

The results presented here demonstrate our ability to do full double-null simulations with varying degrees of magnetic imbalance, including the effect of cross-field drifts and self-consistent electrostatic potential. Future work will focus on a detailed comparison of simulation results with experimental data.

\section{Acknowledgements}

This work was performed under the auspices of the United States Department of Energy by the Lawrence Livermore National Laboratory under contract number W7405-ENG-48 and by General Atomics under contract number DE-AC03-89ER51114.

\section{References}

[1] Rognlien; T.D., Porter, G.D., Ryutov, D.D., J. Nucl. Mater. 266-269 (1999) 654

[2] Petrie, T.W., Allen, Fenstermacher, M.E., et Al., J. Nucl. Mater. 290-293 (2001) 935

[3] Rognlien, T.D., Brown, P.N., Campbell, R.B., et Al., Contrib. Plasma Phys. 34 (1994) 362

[4] Rognlien, T.D., Ryutov, D.D., Mattor, N., Porter, G.D., Phys. Plasmas 6 (1999) 1851

[5] Rensink, M.E., Allen, S.L., Porter, G.D., Rognlien, T.D., Contrib. Plasma Phys. 40 (2000) 302

[6] Rensink, M.E., Kugel, H., Maingi, R., et al., J. Nucl. Mater. 290-293 (2001) 706 


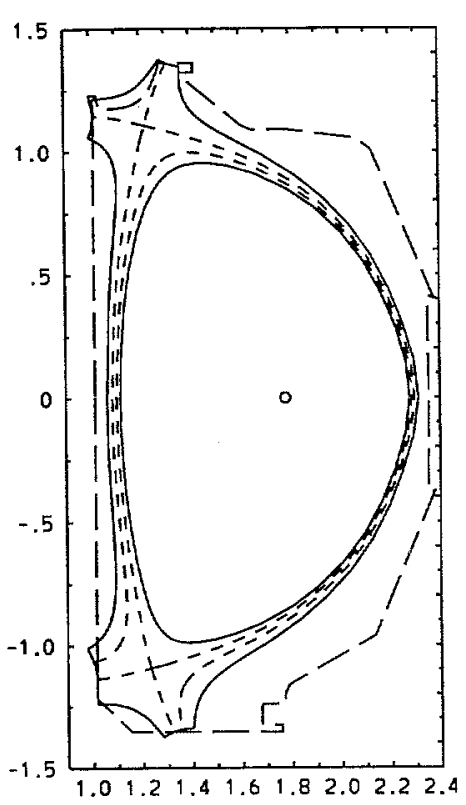

Fig. 1: Simulation domain, separatrices for $\mathrm{dRsep}=-1 \mathrm{~cm}$ and limiting surface in the DIII-D tokamak.

Received September 6, 2001.

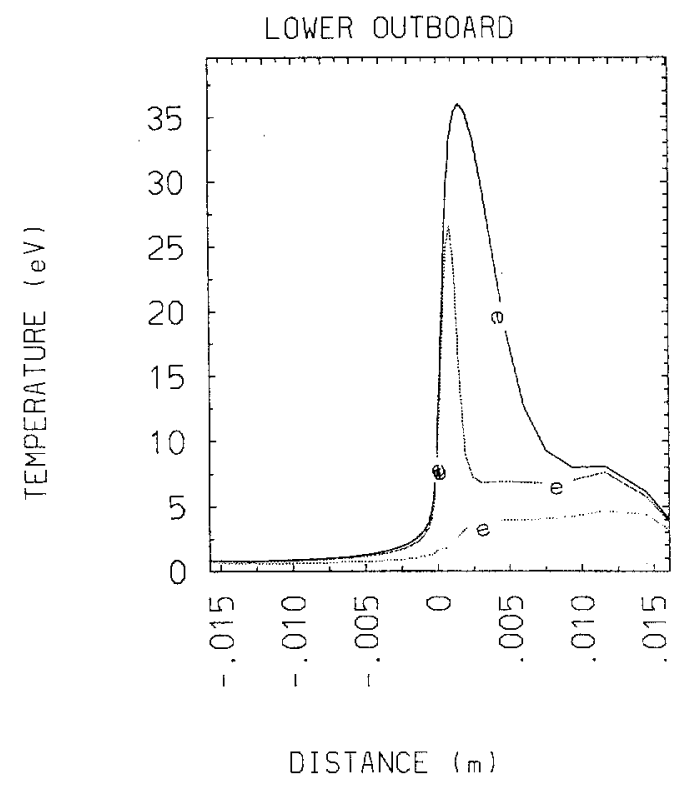

Fig. 2: Electron temperature at the lower outboard divertor plate for various $R_{p}$ with $\mathrm{dRsep}=0$. 

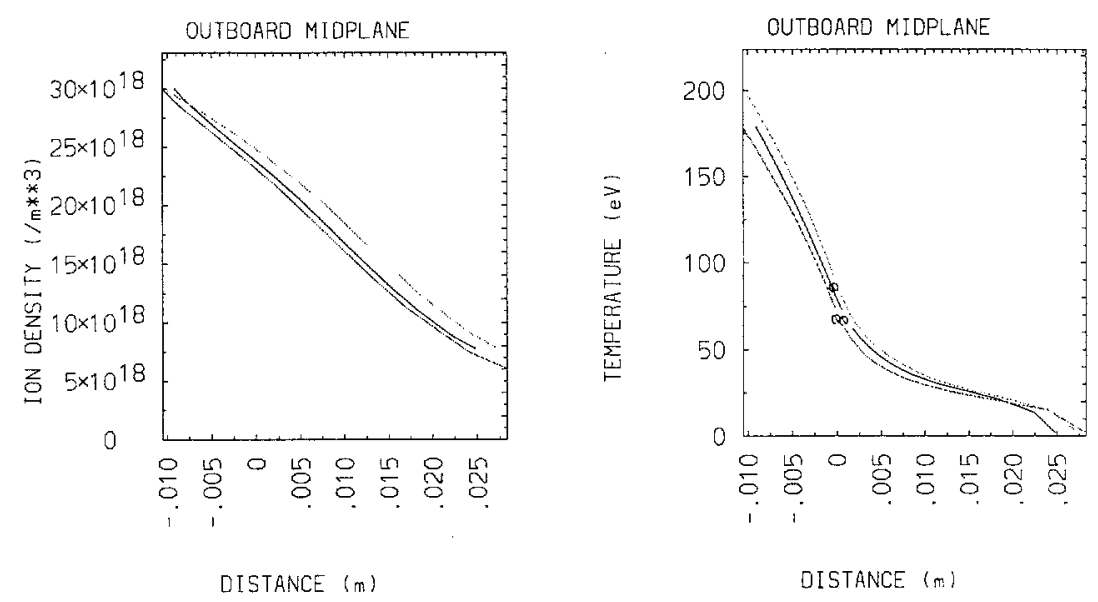

Fig. 3: Outboard midplane plasma profiles for dRsep scan.
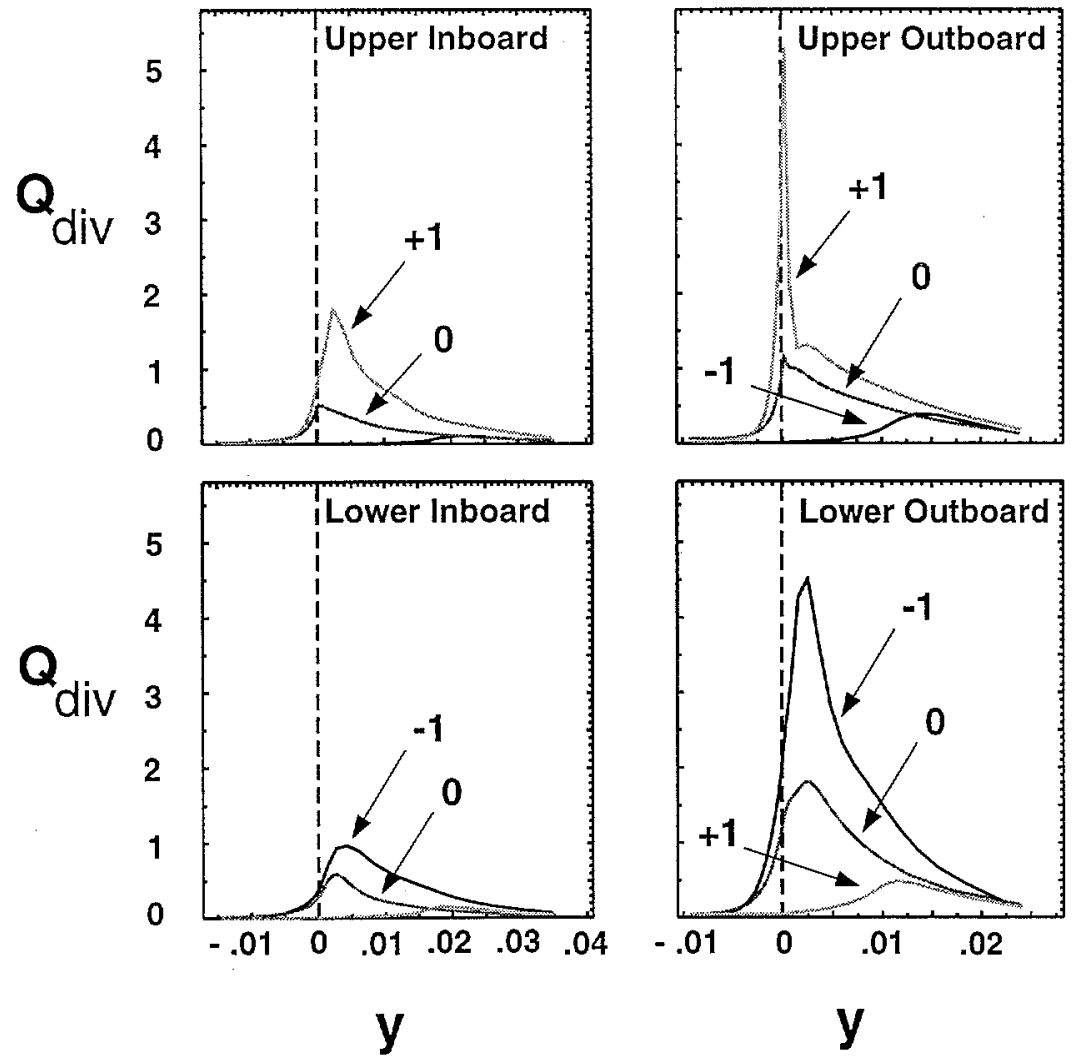

Fig. 4: Divertor plate heat flux profiles, $\mathrm{Q}_{\text {div }}\left(\mathrm{MW} / \mathrm{m}^{2}\right)$ versus $y(m)$, for dRsep scan. The spatial coordinate is the radial position relative to the separatrix strike point (mapped back to the midplane). The various profiles are labelled by the dRsep value for the magnetic configuration. 